\title{
eEnvironment: Reality and Challenges for eEnvironment Implementation in Europe
}

\author{
Jiří Hřebíček ${ }^{1}$ and Werner Pillmann ${ }^{2}$ \\ ${ }^{1}$ Masaryk University, Institute Biostatistics and Analyses, \\ Kotlářská 2, 61137 Brno, Czech Republic \\ ${ }^{2}$ International Society for Environmental Protection, \\ Bechardgasse 24/12, A-1030 Vienna, Austria \\ hrebicek@iba.muni.cz, pillmann@isep.at
}

\begin{abstract}
The White Paper on eEnvironment introduced the content of eEnvironment at the Ad hoc Committee on eDemocracy of the Council of Europe in 2007. The Recommendation CM/Rec(2009)1 of the Committee of Ministers of the Council of Europe to member states on electronic democracy (eDemocracy) specified eEnvironment in more detail. The objective is that any citizen can be informed about environmental matters and can use this information for active participation in decision making and environmental protection.

Now, eEnvironment is one of the pillars of eDemocracy and a member in the "eFamily" like eParticipation and eGovernment. The paper describes the reality and challenges for eEnvironment implementation with respect to the Digital Agenda for Europe and the European eGovernment Action Plan 2011-2015. Furthermore it formulates some ideas for embedding eEnvironment in a Shared Environmental Information System and linked it to the vision of a Single Information Space in Europe for the Environment.
\end{abstract}

Keywords: eEnvironment, eGovernment, eDemocracy, SISE, SEIS, GMES, GEOSS, Europe 2020, Digital Agenda for Europe, European eGovernment Action Plan.

\section{Introduction}

The White Paper on eEnvironment ${ }^{1}$ introduced the content of eEnvironment at the Ad hoc Committee on eDemocracy of the Council of Europe in 2007. This paper outlines eEnvironment as the part of eDemocracy ${ }^{2}$ [1], a framework of Shared Environmental Information System (SEIS) ${ }^{3}$ [2], Global Monitoring for Environment and Security $(\text { GMES })^{4}$ and Global Earth Observation System of Systems (GEOSS) ${ }^{5}$ [3], [4] and the

\footnotetext{
${ }^{1}$ http://www.bmeia.gv.at/fileadmin/user_upload/bmeia/media/AOes/ e-Democracy/4575_18__eacces_to_environm__info.pdf

${ }^{2}$ http://en.wikipedia.org/wiki/E-democracy

${ }^{3} \mathrm{http} / / /$ ec.europa.eu/environment/seis/index.htm

${ }^{4} \mathrm{http} / / /$ www.gmes.info/

${ }^{5}$ http://www.earthobservations.org/gci_gci.shtml
} 
important part of the Single Information Space in Europe for the Environment (SISE) ${ }^{6}$ [2], [5] and introduces current trends in the European Union (EU). Both the visions and challenges of eEnvironment and its potential for further sustainable development of the Environment are discussed. It takes into account tasks and roles of a Digital Agenda for Europe (DAE), cross-border eEnvironment services, the SEIS as a part of the Europe 2020 strategy and the European eGovernment Action Plan 2011-2015 (COM(2010) 743). To accomplish the goals of the EU 2020 Strategy and its flagship initiatives, Innovation Union ${ }^{7}$ and DAE, we need advanced communication infrastructures, information technologies, smart applications and services that should be based on a new generation of networks, on the Internet of the Future ${ }^{8}$.

Therefore, shared environmental data, information and services will be combined in eEnvironment with environmental knowledge for public in order to participate and support government decisions to foster environmental protection and sustainable development in the EU.

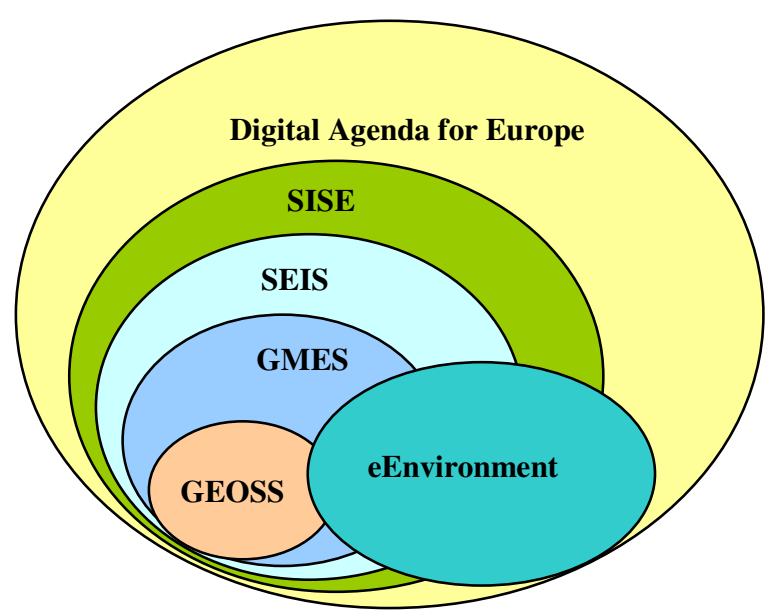

Fig. 1. eEnvironment as the subset of a Digital Agenda for Europe, SISE, SEIS, GMES and GEOSS

\section{Introduction to eEnvironment Vision}

\section{1 eEnvironment and eDemocracy}

The Recommendation CM/Rec(2009)1 of the Committee of Ministers of the Council of Europe to member states on electronic democracy (eDemocracy) of 18 February 2009 settled out recommendations, principles and guidelines concerning eDemocracy which are designed to apply to eDemocracy the democracy and human rights principles established, inter alia, by existing Council of Europe instruments and other international instruments.

\footnotetext{
${ }^{6} \mathrm{http} / / /$ ict-ensure.tugraz.at/en/index.php/ensure/Content2/SISE

${ }^{7} \mathrm{http}$ ://ec.europa.eu/research/innovation-union/index_en.cfm

${ }^{8} \mathrm{http} / / / \mathrm{www}$. future-internet.eu/
} 
It determined 72 principles, rules and regulatory frameworks of eDemocracy in the Appendix to Recommendation CM/Rec(2009)1. It also includes Principle 40 of eDemocracy, where is officially specified eEnvironment as: "eEnvironment is the use and promotion of Information and Communication Technology (ICT) for the purposes of environmental assessment and protection, spatial planning, and the sustainable use of natural resources, and includes public participation. Using ICT to introduce or enhance public participation can improve democratic governance in respect of environmental issues."

This principle was specified in the Explanatory memorandum to Recommendation $\mathrm{CM} / \operatorname{Rec}(2009) 1$ of the Committee of Ministers to Member States on eDemocracy, where it is described in the Sectors on eDemocracy as items 87-89:

87. eEnvironment includes the use of ICT-based systems for access to and the dissemination of environmental data and information as well as the establishment of ICT-supported monitoring systems and repositories for environmental knowledge. eEnvironment thus makes it possible to forecast and monitor the impact of natural and man-made factors and other pressures on the environment, and to determine the current state of the environment, which in turn makes it easier to formulate potential responses because it is possible to draw on a broader, more widely disseminated knowledge base.

88. Spatial planning and spatial cohesion are both basic components of the eEnvironment field, and as such constitute major challenges for nation states and regional and local authorities. In May 2008, the Congress of Local and Regional Authorities of the Council of Europe adopted a report and recommendation on "Electronic democracy and deliberative consultation on urban projects.".

89. The Aarhus Convention ${ }^{10}$ includes provisions calling on contracting parties to use electronic information tools to provide public access to environmental information. To this end, the Parties to the Aarhus Convention set up a task force to facilitate its implementation through the effective use of ICT tools (Aarhus Clearing house ${ }^{11}$ ) designed to provide public access to environmental information.

The above eDemocracy principles for eEnvironment were reflected in European legislation and influence the idea of the SISE and particularly for the SEIS [4], [5], where very important role had recent development which has been the entering in force of the INSPIRE Directive 2007/2/EC in May $2007^{12}$ supporting the 88. principle. This established an infrastructure for spatial information in Europe to support environmental policies in EU, and policies or activities which may have an impact on the environment ${ }^{13}$. It is supported by the prototype INSPIRE geoportal ${ }^{14}$ for discovery

\footnotetext{
${ }^{9}$ http://wcd.coe.int/ViewDoc.jsp?id=1278871\&Site=Congress \&BackColorInternet=e0cee1\& BackColorIntranet=e0cee1\&BackColorLogged=FFC679

${ }^{10} \mathrm{http}: / /$ www.unece.org/env/pp/

${ }^{11} \mathrm{http} / / /$ aarhusclearinghouse.unece.org/

${ }^{12} \mathrm{http} / / /$ eur-lex.europa.eu/LexUriServ/LexUriServ.do?uri=CELEX:32007L0002:EN:NOT

${ }^{13} \mathrm{http}: / /$ inspire.jrc.ec.europa.eu/index.cfm
} 
and viewing of spatial data sets and services. The prototype INSPIRE geoportal currently accesses a limited number of discovery and view services and therefore only a few metadata for spatial data sets and services can be found and viewed. These will increase as more services become available from the EU Member States.

\subsection{Development of eEnvironment Infrastructure}

The development of an ICT infrastructure for the SISE and the SEIS (generally for eEnvironment) started during the Sixth Framework Programme (FP6) ${ }^{15} 2002-2006$. The majority of funding under the respective actions in ICT went into technical preparation of the SISE (architectures, concepts, services, reference models etc). It has continued in the Seven Framework Programme (FP7) ${ }^{16} 2007$ - 2013, particularly in the last two years to permit an easy discovery of European environmental service nodes on the web and their adaptive chaining (or composition) on demand.

The EU actively supports the concept of SEIS and SISE through its research programmes. In previous (e.g. FP6) and the currently active (FP7) framework programme, there is a multitude of research projects (DIADEM, DIVINE, EarthLookCZ, GEM-CON-BIO, GENESIS, GIGAS, HUMBOLDT, ICT-ENSURE, INTAMAP, LENVIS, ORCHESTRA, SANY, TESS, ${ }^{17}$ that address key aspects of a common environmental information system supporting the 87 . and 89 principles of eDemocracy. The same is also true for the CIP $^{18}$ umbrella programme and especially its ICTPSP programme ${ }^{19}$.

It took full advantage of international open standards including the program Interoperability Solutions for European Public Administrations (ISA) ${ }^{20}$. It capitalizes on the experience gained since 1999 with the two previous programmes IDA II (Interchange of Data between Administrations) and IDABC (Interoperable Delivery of panEuropean eGovernment services to public Administrations, Businesses and Citizens). ISA will run from 2010 to 2015 with a financial funding of 164 million Euros.

The development of the SISE in FP7 included generic semantics frameworks and dynamic ontology services for the discovery of and access to distributed environmental resources in a multilingual multi-domain context.

Challenges and new tasks of eEnvironment were summarised by authors of [5] in 2010:

- Establish eEnvironment national/regional environmental information web centres in the Member States of EU or equivalent sources of information as the part of the SEIS that will stimulate and promote public access to information and public participation in environmental decision-making; promote access to electronically stored environmental information by establishing and maintaining community web access points;

\footnotetext{
${ }^{14}$ http://www.inspire-geoportal.eu/index.cfm

${ }^{15} \mathrm{http} / / /$ ec.europa.eu/research/fp6/index_en.cfm

${ }^{16} \mathrm{http}: / /$ ec.europa.eu/research/fp7/index_en.cfm

${ }^{17} \mathrm{http} / / /$ ec.europa.eu/environment/seis/related_projects.htm

${ }^{18} \mathrm{http} / / / \mathrm{ec}$. europa.eu/cip/

${ }^{19} \mathrm{http} / / /$ ec.europa.eu/cip/ict-psp/index_en.htm

${ }^{20} \mathrm{http} / / / \mathrm{ec}$. europa.eu/isa/
} 
- Establish one-stop access point(s) for citizen and related eGovernment services $^{2 l}$, with coordinated input from the relevant public authorities and/or linkages to other similar sites;

- Develop human capacity for the use of ICT tools of SISE, SEIS, GMES and GEOSS to promote the implementation of eEnvironment through comprehensive and forward-looking training and education strategies for public officials;

- Promote the European Commission's efforts to develop the institutional capacities of public authorities to monitor, collect, organize, store and disseminate environmental data, information, services and knowledge in an easily accessible and user-friendly manner in GMES;

- Ensure the availability of commonly readable, user-friendly and easily transferable formats (as standards) of SISE, SEIS, GMES and GEOSS for environment-related data, information, services and knowledge. Develop and apply comprehensive ICT tools of eEnvironment, including specific training programmes linking the use of ICT tools to the promotion of good environmental governance in EU member states;

- Promote the involvement of different stakeholders representing both SEIS, GMES and GEOSS providers and its users, including civil society and private sector institutions, in the development and use of ICT tools with a view to improving the accessibility, as well as the availability, of environmental information and knowledge to the public;

- Maintain a national SEIS web site with data and information related to the nationwide implementation of eEnvironment, which will serve also as the national node of the SEIS clearing-house mechanism;

- Designate national/regional contact points in SEIS and GMES responsible for collecting, managing and updating the information contained in the national node and for providing the necessary information for the central node of the SEIS clearing-house mechanism at EEA, and undertake to disseminate information to the public on the clearing-house mechanism; and

- Develop capacity for public officials managing and updating information for the national node of SEIS in the Shared European National State of the Environment ${ }^{22}$ (SENSE) project, and for providing the necessary information for the central node of the clearing-house mechanism at European Environment Agency (EEA).

- Develop methods and protocols for service chaining in SISE and for the management of the effects of uncertainty propagation through service chaining, which will be included into the ICT infrastructure for eEnvironment.

The eEnvironment implementation through SEIS and the "State of Environment Report" (SOER) $2010^{23}$ has contributed to high quality information and services

${ }^{21} \mathrm{http} / / /$ ec.europa.eu/information_society/activities/egovernment/index_en.htm

${ }^{22} \mathrm{http} / / / \mathrm{svn}$.eionet.europa.eu/projects/Zope/wiki/SENSE

${ }^{23}$ SOER 2010, http://www.eea.europa.eu/soer, was the fourth State and Outlook Report on the European environment produced by the European Environment Agency (EEA). This "report" produced by the EEA for 2010 , covered 38 countries, on the current state of the environment, how we got to that state, what that state might be by 2020 , what is being done and what could be done to improve that state. 
provision and it will thus provide Europe's backbone infrastructure for eGovernment / eParticipation $^{24}$ / eDemocracy services in the Environment Matters; it will also provide a powerful ICT tools to support rapid knowledge-based decision making for sustainable development at all levels (national, regional, local), as integrated information from various environmental impacts (related with economic and social items) will be available on real-time.

It will boost competiveness and innovation of European ICT industry. Finally, SOER 2010 is a substantial contribution of EU to global ICT tools under development (in Digital Agenda for Europe goals implementation) in order to support global governance for sustainable development, such as is done in the GEOSS.

\section{3 eEnvironment and Digital Agenda for Europe}

The Digital Agenda for Europe (COM (2010) 245$)^{25}$ is one of the seven flagship initiatives of the Europe 2020 Strategy $(\operatorname{COM}(2010) 2020 \text { final })^{26}$, that set out to define the key enabling role that the use of ICTs will have to play if Europe wants to succeed in its ambitions for 2020. It outlines seven priority areas for action, namely:

1. Creating a Digital Single Market to deliver the benefits of the digital era.

2. Improving the framework conditions for interoperability between ICT products.

3. Enhancing Internet trust and security.

4. Increasing access to fast and ultra fast Internet.

5. Boosting cutting-edge research and innovation in ICTs.

6. Enhancing digital literacy, skills and social inclusion.

7. Applying ICTs to address social challenges such as climate change, rising healthcare costs and the ageing population.

In its Key Action 16 and other actions the Digital Agenda for Europe proposes a Council and Parliament Decision by 2012 to ensure mutual recognition of e-identification and e-authentication across the EU, based on online "authentication services" to be offered in all Member States (which may use the most appropriate official citizen documents - issued by the public or the private sector).

The Digital Agenda for Europe sets eGovernment within a comprehensive set of measures aimed at exploiting the benefits of ICT across Europe. At a time of highly constrained public resources, ICT can help the public sector develop innovative ways of delivering its services to citizens while unleashing efficiencies and driving down costs.

The availability of innovative technologies such as social networks has increased the expectations of citizens in terms of responsiveness when accessing all kinds of services on line. However, cross-border eGovernment services are few and, even where eGovernment services are offered, the majority of EU citizens are reluctant to use them. There is clearly a need to move towards a more open model of design, production and delivery of online services, taking advantage of the possibility offered by

\footnotetext{
${ }^{24} \mathrm{http} / / /$ ec.europa.eu/information_society/activities/egovernment/policy/eparticipation/ index_en.htm

${ }^{25} \mathrm{http}$ ://eur-lex.europa.eu/LexUriServ/LexUriServ.do?uri=COM:2010:0245:FIN:EN:PDF

${ }^{26} \mathrm{http}$ ://eur-lex.europa.eu/LexUriServ/LexUriServ.do?uri=COM:2010:2020:FIN:EN:PDF
} 
collaboration between citizens, entrepreneurs and civil society. The combination of new technologies, open specifications, innovative architectures and the availability of public sector information can deliver greater value to citizens with fewer resources.

Furthermore the Digital Agenda for Europe (DAE) proposes:

- Support by 2012 seamless cross-border eGovernment services in the single market through the Competitiveness and Innovation Programme and Interoperability Solutions for European Public Administrations (ISA) Programme ${ }^{27}$ issued from the ISA;

- $\quad$ Review by 2011 of Directive 2003/4/EC "Public Access to Environmental Information";

- Work with Member States and stakeholders to implement cross-border eEnvironment services, notably advanced sensor networks;

- Define by 2011 concrete steps in a White Paper on how to inter-connect eprocurement capacity across the single market; and

- Set an example of open and transparent eGovernment by creating and implementing an ambitious eCommission 2011-2015 action plan ${ }^{28}$ including full electronic procurement.

Member States of the EU should follow these tasks formulated by the DAE i.e.:

- $\quad$ Make eGovernment services fully interoperable, overcoming organizational, technical or semantic barriers and supporting communication protocol IPv6 $6^{29}$;

- Ensure that the Points of Single Contact function as fully fledged eGovernment centres beyond the requirements and areas covered by the Services Directive [7];

- Agree by 2011 on a common list of key cross-border public services that correspond to well-defined needs - enabling entrepreneurs to set up and run a business anywhere in Europe independent of their original location, and allowing citizens to study, work, reside and retire anywhere in the EU. These key services should be available online by 2015 .

\section{4 eEnvironment Services in the Digital Agenda for Europe}

The term "eEnvironment services" in the Digital Agenda for Europe (DAE) includes all computer-based tools that support the environment conservation process and encompasses services ranging from the simple provision of environmental information to sophisticated reporting and information processing.

According to the DAE eEnvironment services that focus on ICT development in the environment domain are somewhat underdeveloped or "fragmented along national borders".

The current approach to these challenges is embedded in the SEIS Communication $(\mathrm{COM} / 2008 / 0046 \text { final })^{30}$ and some recent projects Reportnet $^{31}$, PortalU ${ }^{32}$ and

\footnotetext{
${ }^{27} \mathrm{http}: / / \mathrm{ec}$. europa.eu/isa/

${ }^{28} \mathrm{http}$ ://ec.europa.eu/information_society/activities/egovernment/action_plan_2011_2015/ docs/action_plan_en_act_part1_v2.pdf

${ }^{29} \mathrm{http}: / / \mathrm{ipv} 6 . \mathrm{com} /$

${ }^{30} \mathrm{http}$ ://eur-lex.europa.eu/LexUriServ/LexUriServ.do?uri=CELEX:52008DC0046:EN:NOT
} 
$\mathrm{WISE}^{33}$ ). The SEIS recognises the need to address several key steps in the ways data are created and shared, where the notion of centralised systems for reporting "are progressively replaced by systems based on access, sharing and interoperability".

The eEnvironment services can be a valuable tool for interested persons, researchers, and decision makers. They can address general policy-related subjects, or specific environmental study areas [6]. These areas can be grouped as follows:

- Air quality.

- Ozone depletion.

- Climate change.

- Biodiversity.

- Terrestrial.

- Water.

- Waste.

- Agriculture.

- Energy.

- Fishery.

- Transport.

eEnvironment services, as a category of eGovernment services, are either still under-developed, or fragmented along national borders ${ }^{34}$. This is a challenge that the digitalization of public services is facing as a whole. In extension to overcome these barriers, firstly the EU law in this area among others should be reviewed and modernized. Secondly, innovative solutions such as advanced sensor networks can help fill gaps in the required environmental data.

The project NESIS ${ }^{35}$ has identified requirements and ICT solutions for environmental information sharing, refers to the European ICT policy context (top-down approach), as well as to the specific needs and related solutions of environmental data-sharing, as dealt by (bottom-up approach) in recent projects and initiatives.

The top-down approach grounds on the political context/evolution and refers to the priorities of the current EC initiatives. Overall, concerns about information-sharing in public agencies and government in the EU are grounded in the activities of eGovernment. At the EU level, the European Interoperability Strategy (EIS) ${ }^{36}$ was devised to ensure appropriate governance, organisation and processes in line with the EU policies and objectives, together with trusted information exchange. The ISA carry

${ }^{31} \mathrm{http}: / / \mathrm{www} . e i o n e t . e u r o p a . e u / r e p o r t n e t$

32 http://www.portalu.de/ingrid-portal/portal/_ns:YUxhbmd1YWdlU3dpdGNofGMwfGQw/

${ }^{33} \mathrm{http} / / / \mathrm{www}$.water.europa.eu/

${ }^{34}$ Austria: http://www.nesis.eu/index.php?option=com_wrapper\&view=wrapper\&Itemid=157, Czech: http://www.nesis.eu/index.php?option=com_wrapper\&view=wrapper\&Itemid=147, France: http://www.nesis.eu/index.php?option=com_wrapper\&view=wrapper\&Itemid=163, Germany: http://www.nesis.eu/index.php?option=com_wrapper\&view=wrapper\&Itemid=146, Sweden: http://www.nesis.eu/index.php?option=com_wrapper\&view=wrapper\&Itemid $=154$ UK: http://www.nesis.eu/index.php?option=com_wrapper\&view=wrapper\&Itemid=190

${ }^{35} \mathrm{http}: / /$ www.nesis.eu/

${ }^{36} \mathrm{http} / / /$ ec.europa.eu/idabc/en/document/7772.html 
forward the European eGovernment Action Plan from 2010 to $2015^{37}$, with a particular focus on "back-office" solutions that support EU policies and activities and avoid barriers to interoperability across borders.

The EIS suggested that a top-down view and definition of criteria and contents should be accompanied by actions supporting concrete projects at a grassroots level (bottom-up approach), with similar considerations present in the ISA. By addressing real examples, that test existing guidelines against concrete needs, it is hoped that new and possibly reusable services/tools can be produced to meet these demands in a range of contexts.

This brings an impulse for new progress in the area of eEnvironment. The plan to provide eEnvironment communication to all citizens of the EU in the DAE will enable citizens to be informed about environmental matters and to use monitored, collected, processed, evaluated and visualized data, information and knowledge, and thus allow an active participation of citizens in decision making in environmental protection and sustainable growth.

SEIS proposed the set of principles on the basis of which the collection, exchange and use of environmental data and information should be organised in the future:

- Manage information close to source.

- Share information.

- Support fulfilment of reporting obligations.

- Assess state of the environment.

- Assess effectiveness of policies.

- Support design of new policies.

- Support (public) participation.

- Allow comparison on appropriate geographic scale.

- Make information on the environment publicly available.

- Support multilingualism.

- $\quad$ Base IT on open source.

A key step in the implementation of the SEIS (eEnvironment services) approach will be to modernise the way in which information required in various pieces of environmental legislation is made available, through a legislative instrument that should follow the SEIS Communication and probably revise the current "Standardised reporting directive" No. 91/692/EC ${ }^{38}$. Such a revision should also provide an immediate opportunity to repeal a limited number of obsolete reporting requirements, and lead to further simplification and modernization along the following lines [9]:

- to help to stimulate further streamlining of information requirements in thematic environmental legislation, with a coherent and up-to-date overall framework;

- to stimulate similar developments in international conventions, which according to estimates are responsible for around $70 \%$ of environmental reporting requirements to which EU Member States are subject;

\footnotetext{
${ }^{37}$ http://ec.europa.eu/information_society/activities/egovernment/ action_plan_2011_2015/index_en.htm

${ }^{38}$ http://eur-lex.europa.eu/LexUriServ/site/en/consleg/1991/L/01991L0692-20031120-en.pdf
} 
- to encourage improvements in the way that data collection and exchange within EU Member States is organized.

\section{5 eEnvironment Services and European Neighbourhood}

The EEA was assigned by EC Directorate-General EuropeAid Co-operation Office (EC/DG AIDCO $)^{39}$ to carry out a project for gradually extending the SEIS principles (eEnvironment services) to the European Neighbourhood Policy ${ }^{40}$ to South and East neighbours and the Russian Federation (ENP). The ENPI-SEIS project ${ }^{41}$ aims to improve environmental monitoring and data and information sharing by gradually extending the SEIS principles to the European neighbourhood. The project will run over the period 2010-2014.

The overall goal of the ENPI-SEIS project is to promote the protection of the environment in the countries of the ENP area. In order to achieve this, the project aims towards a set of measurable and specific objectives:

- to identify or further develop environmental indicators and scorecards suitable for the design and review of environmental policies, supporting the monitoring and compliance with various national, regional and international obligations and targets;

- to improve capacities in the field of monitoring, collection, storage, assessment, and reporting of environmental data in the relevant environmental authorities including the national statistical systems, in compliance with reporting obligations to international agreements and in coordination with relevant regional initiatives;

- to set up national and regional environmental information systems in the countries of the ENP area that are in line with the SEIS, and

- to track progress of the regional environmental initiatives (ENP, Eastern Partnership, Horizon 2020) ${ }^{42}$.

The main outcomes of the ENPI-SEIS project will address the three SEIS components - cooperation, content and infrastructure - through enhanced networking with the national capacities on environmental information. Furthermore, it will promote open, public access to information through compatible and freely available exchange tools.

\section{6 eEnvironment and Open Government Data Initiative}

Many projects supporting the ambitious efforts of SISE and SEIS (including eEnvironment services), which are now in progress, were presented during the European conference of the Czech Presidency of the Council of the EU: Towards eEnvironment - Opportunities of SEIS and SISE: Integrating Environmental Knowledge in Europe ${ }^{43}$ in Prague on March 25-27, 2009 [8].

\footnotetext{
${ }^{39} \mathrm{http}: / /$ ec.europa.eu/europeaid/index_en.htm

${ }^{40} \mathrm{http} / / /$ ec.europa.eu/europeaid/where/neighbourhood/index_en.htm

${ }^{41} \mathrm{http} / / /$ enpi-seis.ew.eea.europa.eu/

${ }^{42} \mathrm{http} / / / \mathrm{www} . \mathrm{h} 2020$. net/en/review-monitoring-and-research/the-project-enpi-seis.html

${ }^{43} \mathrm{http} / / /$ www.e-envi2009.org
} 
The Conference Sharing Environmental Information ${ }^{44}$ was held in Brussels on November 29,2010 - December 1,2010 and brought in its Conclusion a new initiative connected to Open Government data: "8. Initiatives towards enhancing the availability of data and information produced or commissioned by government or government controlled entities such as the Open Government data initiative ${ }^{45}$ is welcomed."

This conference brought together representatives from the EEA member and cooperating countries, EEA and the European Commission (EC). The participants reflected mainly on the implementation of the SEIS. In the conference conclusions, the participants encouraged the EC to publish the SEIS Implementation Plan as soon as possible.

They also emphasised the benefits of mutually supportive interaction between SEIS, INSPIRE and GMES processes. The participants also recommended that SEIS, through the use of relevant ICT, should be closely connected to the Digital Agenda for Europe as part of the EU strategy 2020.

The public sector holds a gold mine of environmental information. Much of environmental data that public authorities gather are not used or serve only a limited purpose. The release of non personal public data (environmental, geographical, demographic, statistical data etc...) in particular when provided in a machine readable format allows citizens, and businesses to find new ways to use it and to create new innovative products and services.

The European eGovernment Action Plan 2011 - 2015 has given the central role of national governments in the implementation of this action plan the EC's main responsibility is to improve the conditions for development of cross-border eGovernment services provided to citizens and businesses regardless of their country of origin. This includes establishing pre-conditions, such as interoperability, eSignatures ${ }^{46}$ and eIdentification ${ }^{47}$. These services strengthen the internal market and complement EU legislative acts and their effectiveness ${ }^{48}$ in a number of domains where ICT can improve delivery of services; such as in procurement, justice, health, environment, mobility and social security, and support the implementation of citizens' initiatives with ICT tools.

The vision Open Government data is fulfilled by the European Open Government data initiative (OGDI) ${ }^{49}$ that is a free, open-source, cloud-based collection of software assets that government organizations can take advantage of. They can load and store public data using the Microsoft Cloud $^{50}$, using the Windows Azure Platform ${ }^{51}$.

\footnotetext{
${ }^{44} \mathrm{http}$ ///ew.eea.europa.eu/meetings-and-events/sharing-environmental-information

${ }^{45} \mathrm{http}: / /$ opengovernmentdata.org/

${ }^{46} \mathrm{http} / / /$ ec.europa.eu/information_society/policy/esignature/index_en.htm

${ }^{47} \mathrm{http} / / /$ ec.europa.eu/information_society/policy/esignature/action_plan/index_en.htm

${ }^{48}$ Such EU legislative acts include: the Services Directive (2006/123/EC), the eSignatures Directive (1999/93/EC), the Procurement Directives (2004/17/EC and 2004/18/EC), the Data Protection Directive (95/46/EC), the Directive on the re-use of public sector information (2003/98/EC), the Infrastructure for Spatial Information in the European Community (IN SPIRE Directive 2007/2/EC), the public access to environmental information Directive (2003/4/EC).

${ }^{49} \mathrm{http}: / / \mathrm{www}$. govdata.eu/en/europeanopen.aspx

${ }^{50} \mathrm{http}: / / \mathrm{www} . \mathrm{microsoft}$. com/en-us/cloud/1/home.aspx?fbid=vL91-4EikW6

${ }^{51} \mathrm{http}: / /$ www.microsoft.com/windowsazure/
} 
eEnvironment legislative background - Directive 2003/98/EC of the European Parliament and of the Council of 17 November 2003 on the re-use of public sector information (PSI Directive) - sets the legislative framework for the re-use of public information. It has introduced a common legislative framework regulating how public sector bodies should make their information available for re-use in order to remove barriers such as discriminatory practices, monopoly markets and a lack of transparency. All 27 EU Member States have implemented the PSI Directive into their national legal orders ${ }^{52}$.

But Open Government is so much more than a legal requirement. Better access to Public Sector Information (PSI) can improve people's quality of life and make how they interface with government much easier. Plus, it can create new businesses and jobs while giving consumers more choice and greater value for money.

PSI is the single largest source of environmental information in Europe. It is produced and collected by public bodies and includes digital maps, meteorological, environmental, legal, traffic, financial, economic and other data. Most of this raw data could be re-used or integrated into new products and services, which we use on a daily basis, such as car navigation systems, weather forecasts, financial and insurance services.

Re-use of PSI means using it in new ways by adding value to it, combining information from different sources, making mash-ups and new applications, both for commercial and non-commercial purposes. Examples include real time traffic information and bus timetables together with maps downloaded to smart phones.

The Directive PSI has introduced a common legislative framework regulating how public sector bodies should make their information available for re-use in order to remove barriers such as discriminatory practices, monopoly markets and a lack of transparency. All 27 EU Member States have implemented the PSI Directive into their national legal orders.

OGDI uses the Windows Azure Platform for Windows Azure Platform to make it easier to publish and use a wide variety of public data from government agencies. OGDI is also a free, open source "starter kit" with code ${ }^{53}$ that can be used to publish data on the Internet in a Web-friendly format with easy-to-use, open Application Program Interfaces (API's) ${ }^{54}$. OGDI-based web API's can be accessed from a variety of client technologies such as Silverlight, Flash, JavaScript, PHP, Python, Ruby, mapping web sites, etc.

Whether citizen wishing to use government data (e.g. environmental data), a government developer, or a "citizen developer", these open API's will enable citizen to build innovative applications, visualizations and mash-ups that empower people through access to government information. This site is built using the OGDI starter kit software assets and provides interactive access to some publicly-available data sets along with sample code and resources for writing applications using the OGDI API's.

\footnotetext{
${ }^{52} \mathrm{http} / / /$ ec.europa.eu/information_society/policy/psi/rules/ms/index_en.htm

${ }^{53}$ http://ogdi.codeplex.com/

${ }^{54}$ Application program interface is a set of routines, protocols, and tools for building software applications.
} 


\section{Vision for Extending eEnvironment to a Single Information Space in Europe for the Environment}

The idea to integrate the immense pan-European diversity of environmental information is a vision. A first step to foster the free flow of environmental information is done by eEnvironment, making distributed information sources available in the Web which meets the needs of administration, politics, research, business and the public.

The objective of the implementation of a Single Information Space in Europe for the Environment (SISE) is only conceivable in the medium term for selected areas of environmental relevance. Requirements and demands for such areas can be found in multiple sources, e.g. in the EU's 6th Environmental Action Plan, the Environmental Policy Reviews and in the Digital Agenda for Europe. Currently the idea of SISE is promoted by list of European projects as ICT-ENSURE ${ }^{55}$, EnviroGrid BlackSee ${ }^{56}$, GENESIS $^{57}$, NaturNet plus ${ }^{58}$, TaToo $^{59}$ and ENVIROFI ${ }^{60}$.

We see SISE as complementary activity to INSPIRE, GMES and SEIS, supporting mainly bottom up building ICT infrastructure for environment. First steps in the design and conceptual detailing of such an information space are done in the FP7 project ICT-ENSURE. The emphasis was put on some focus areas, where ICT are applied in control of Energy Consumption, increasing Energy Efficiency, analyses Climate Change, improve Sustainable Use of Natural Resources, monitor Biodiversity and use ICT for Industrial Ecology and for Sustainable Urban Development.

The FP7 ENVIROFI Future Internet project will address such important issues by specifying the requirements, and building conceptual prototypes, of the specific enablers of the environmental usage area in the Future Internet. It will bring these diverse stakeholder communities together to understand environmentally observed processes with higher spatial resolutions and contextual situation awareness at an unprecedented scale.

The SISE is seen as further step after eEnvironment services are fully implemented for "Public access to Environmental Information" in Europe". A structural design of the SISE including eEnvironment as an essential element can be found in [10].

\section{Conclusion}

This paper outlined some reality and challenges for eEnvironment implementation in Europe, which are required by the DAE and its implementation plan.

Acknowledgments. The above results have been developed during the ICT-ENSURE project "European ICT Environmental Sustainability Research". ICT-ENSURE was financed under the grant agreement number 224017 of the European Commission's $7^{\text {th }}$ framework programme, by DG-INFSO Unit "ICT for Sustainable Growth".

\footnotetext{
${ }^{55} \mathrm{http}: / /$ www.ict-ensure.eu

${ }^{56} \mathrm{http}: / /$ www.envirogrids.net/

${ }^{57} \mathrm{http}: / / \mathrm{www}$.genesis-fp7.eu/

${ }^{58} \mathrm{http}: / / \mathrm{www}$. naturnet.org/simplecms/?menuID=66\&action=article\&presenter=Article

${ }^{59} \mathrm{http}: / /$ www.tatoo-fp7.eu/tatooweb/

${ }^{60} \mathrm{http} / / /$ www.envirofi.eu/
} 


\section{References}

1. Karamagioli, E., Hřebíček, J., Legat, R., Schleidt, K.: Environmental Democracy via ICT; Public Participation via ICT Towards Sustainable Development. In: Leitner, C., Makolm, M.H.J., Traunmüller, R. (eds.) Eastern European elGov Days 2010. Unleashing the Potential of e-Government: Beyond Simple Patterns of Electronic Service Delivery, pp. 177194. Austrian Computer Society, Wien (2010)

2. Hrebicek, J., Pillmann, W.: Shared Environmental Information System and Single Information Space in Europe for the Environment: Antipodes or Associates? In: European conference of the Czech Presidency of the Council of the EU: Towards eEnvironment Opportunities of SEIS and SISE: Integrating Environmental Knowledge in Europe, pp. 447-458. Masaryk university, Brno (2009)

3. Pillmann, W., Hrebicek, J.: Information Sources for a European Integrated Environmental Information Space. In: 23. International Conference on Informatics for Environmental Protection. EnviroInfo 2009. Environmental Informatics and Industrial Environmental Protection: Concepts, Methods and Tools, pp. 341-352. Shaker Verlag, Aachen (2009)

4. Pillmann, W., Hrebicek, J.: ICT for Public Access to Environmental Information. In: 8. Eastern European elGov Days 2010. Unleashing the Potential of eGovernment: Beyond Simple Patterns of Electronic Service Delivery, pp. 195-202. Austrian Computer Society, Wien (2010)

5. Hrebicek, J., Legat, R., Schleidt, K.: eDemocracy \& eEnvironment: Reality and challenges for eEnvironment implementation in Europe. In: 8. Eastern European elGov Days 2010. Unleashing the Potential of e-Government: Beyond Simple Patterns of Electronic Service Delivery, pp. 167-176. Austrian Computer Society, Wien (2010)

6. Indicators and fact sheets about Europe's environment, http:// www . eea . europa. eu / data-and-maps / indicators $/ \# c 7=a l 1 \& c 5=\& c 0=10$

7. Handbook on Implementation of the Service Directive, http: / / ec.europa.eu/internal_market/services/docs / services-dir/guides/handbook_en.pdf

8. Hrebicek, J., et al. (eds.): Proceedings of European conference of the Czech Presidency of the Council of the EU: Towards eEnvironment - Opportunities of SEIS and SISE: Integrating Environmental Knowledge in Europe. Masaryk University, Brno (2009)

9. NESIS: Deliverable 6.2 - Towards the ICT implementation of SEIS, http://www.nesis.eu/index.php?option=com_content\& view=article\&id $=142 \&$ Itemid $=125$

10. Pillmann, W., Pick, T., Hrebicek, J., et al.: Conceptual Detailing of a Single Information Space in Europe for the Environment. ICT-ENSURE Deliverable D7.2 (2010), http://ict-ensure.tugraz.at/en/index.php/ensure/ Organisational-Content/Downloads-Resources/Deliverables / WP-7-SISE-Concept-Outline 